\title{
Circulating resistin levels and obesity-related cancer risk: A meta-analysis
}

\author{
Wei-Jing Gong ${ }^{1,2,3}$, Wei Zheng ${ }^{1,2}$, Ling Xiao ${ }^{1,2}$, Li-Ming Tan ${ }^{1,2}$, Jian Song ${ }^{4}$, Xiang- \\ Ping Li ${ }^{5}$, Di Xiao ${ }^{1,2}$, Jia-Jia Cui ${ }^{1,2}$, Xi Li ${ }^{1,2}$, Hong-Hao Zhou ${ }^{1,2}$, Ji-Ye Yin ${ }^{1,2,3}$ and Zhao- \\ Qian Liu ${ }^{1,2,3}$ \\ ${ }^{1}$ Department of Clinical Pharmacology, Xiangya Hospital, Central South University, Changsha, P. R. China \\ ${ }^{2}$ Institute of Clinical Pharmacology, Central South University, Hunan Key Laboratory of Pharmacogenetics, Changsha, P. R. \\ China \\ ${ }^{3}$ Hunan Province Cooperation Innovation Center for Molecular Target New Drug Study, Hengyang, P. R. China \\ ${ }^{4}$ Department of Otolaryngology, Xiangya Hospital, Central South University, Changsha, P.R. China \\ ${ }^{5}$ Department of Pharmacy, Xiangya Hospital, Central South University, Changsha, P.R. China \\ Correspondence to: Zhao-Qian Liv, email: liuzhaoqian63@126.com
}

Ji-Ye Yin, email: yinjiye@csu.edu.cn

Keywords: circulating resistin levels, obesity-related cancer, meta-analysis

Received: March 26, $2016 \quad$ Accepted: July 19, $2016 \quad$ Published: August 04, 2016

\section{ABSTRACT}

Resistin levels have been reported to be abnormal in obesity-related cancer patients with epidemiological studies yielding inconsistent results. Therefore, a metaanalysis was performed to assess the association between blood resistin levels and obesity-related cancer risk. A total of 13 studies were included for pooling ORs analysis. High resistin levels were found in cancer patients $(O R=1.20,95 \% \mathrm{CI}=1.10-1.30)$. After excluding one study primarily contributing to between-study heterogeneity, the association between resistin levels and cancer risk was still significant $(O R=1.18$, $95 \% \mathrm{CI}=1.09-1.28)$. Stratification analysis found resistin levels were not associated with cancer risk in prospective studies. Meta-regression analysis identified factors such as geographic area, detection assay, or study design as confounders to betweenstudy variance. The result of 18 studies of pooling measures on SMD analysis was that high resistin levels were associated with increased cancer risk (SMD $=0.94$, $95 \% \mathrm{CI}=0.63-1.25)$, but not in the pooling SMD analysis of prospective studies. Except for the studies identified as major contributors to heterogeneity by Galbraith plot, resistin levels were still higher in cancer patients (SMD $=0.75,95 \% \mathrm{CI}=$ 0.63-0.87) in retrospective studies. Meta-regression analysis found factors, such as geographic area, BMI-match, size, and quality score, could account for $66.7 \%$ between-study variance in pooling SMD analysis of retrospective studies. Publication bias was not found in pooling ORs analysis. Our findings indicated high resistin levels were associated with increased obesity-related cancer risk. However, it may not be a predictor.

\section{INTRODUCTION}

Obesity and diabetes are considered as important risk factors of cancers. According to a population-based study in 2012, a quarter of the cancer cases possess high body-mass index (BMI) [1]. Among them, prostate, breast, colorectal, thyroid, renal, endometrial, pancreatic and esophageal cancers are identified as obesity-related cancers by a number of epidemiological studies and meta-analyses [2]. Also, individuals with diabetes have significant higher risk of cancer compared with no diabetes [3]. However, the mechanisms underlying the association between obesity or diabetes and cancer development are currently not fully elucidated.

Resistin was first identified by a screening of adipocyte products that were decreased by rosiglitazone in mice. It was considered as the potential link between obesity and diabetes [4]. Resistin expression in prostate 
epithelial cells was also found to be higher in patients with prostate cancer, compared with that in those with benign prostate hyperplasia [5]. Additionally, serum resistin levels were reported to be increased in several cancers, such as breast and colorectal cancers. Studies revealed resistin could promote the proliferation, angiogenesis, and metastasis of cancer cells by stimulating specific signaling pathways including p38 MAPK/NF-kB and PI3K/Akt [68]. Although many studies provided evidence that high resistin levels were associated with the risk of obesityassociated malignancies, some studies observed different results. Many studies showed resistin levels were similar, even lower in cancer patients compare with normal controls. The reasons underlying these heterogeneous findings need to be investigated.

To the best of our knowledge, no systematic review evaluated the association of blood resistin levels with obesity-related cancer risk. More convincing evidence is needed to reveal the role of resistin in obesityrelated cancers. The present study aimed to evaluate the association of circulating resistin levels with the risk of obesity-related cancers by conducting a meta-analysis.

\section{RESULTS}

\section{Literature search}

The procedure of literature selection is presented in Figure 1. We identified 42 potentially relevant papers concerning resistin in relation to cancer risk. 9 papers were excluded because circulating resistin levels were not measured in serum or plasma of the healthy controls or obesity-related cancers. 12 papers were excluded because that they did not provide sufficient information. Finally, for pooling odds ratios (ORs) analysis, 13 articles were included involving 9 retrospective studies and 4 prospective studies [9-21]. With regard to the pooling measures on standardized mean difference (SMD), 17 papers containing 14 retrospective articles and 3 prospective articles [9-14, 19-29] were included.

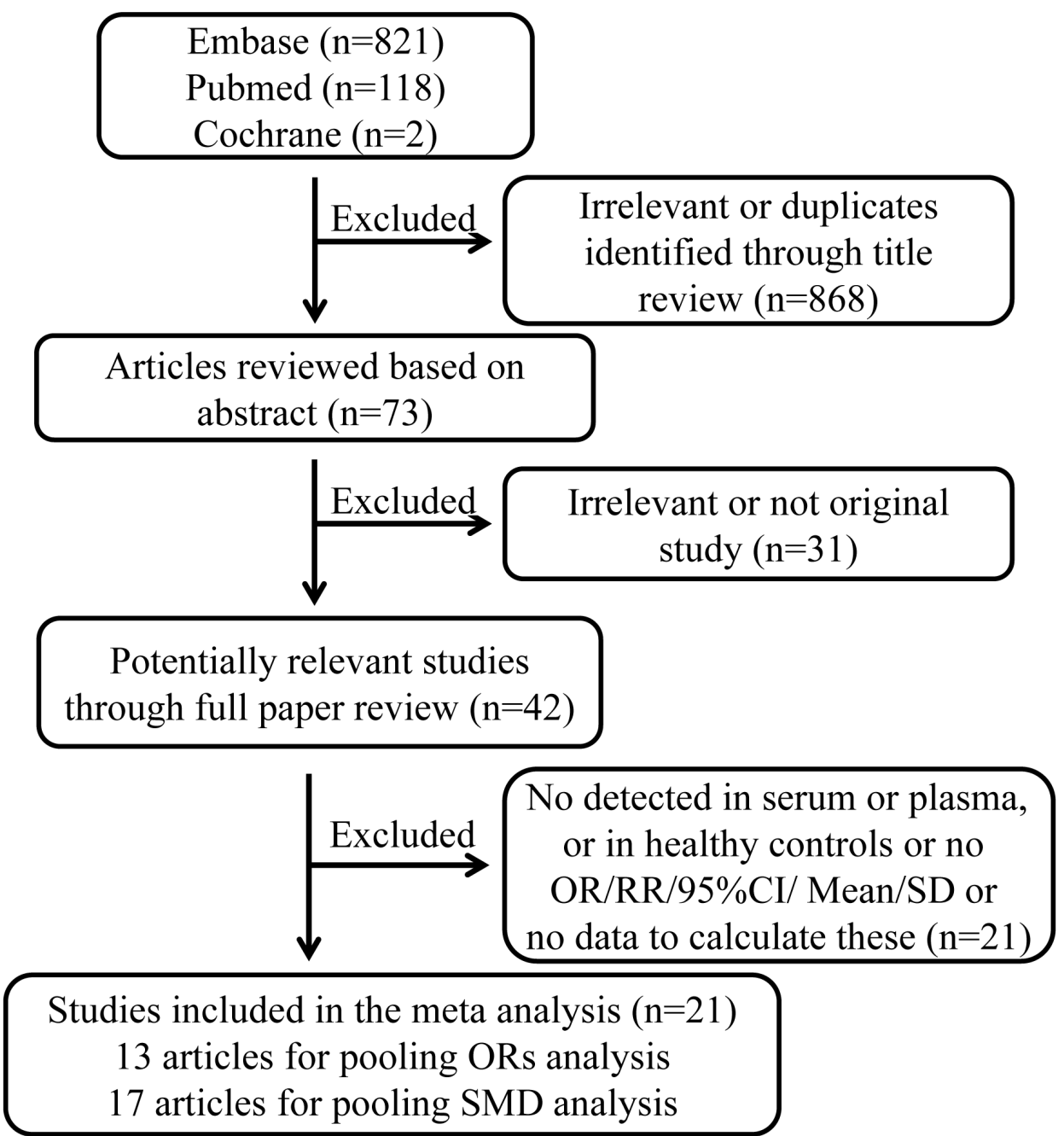

Figure 1: Procedure of article selection. 
Table 1: Characteristics of studies included in pooling ORs analysis

\begin{tabular}{|c|c|c|c|c|c|c|c|c|c|c|}
\hline Author & Year & Country & $\begin{array}{l}\text { Cancer } \\
\text { Type }\end{array}$ & $\begin{array}{l}\text { Control } \\
\text { Source }\end{array}$ & Study Design & $\begin{array}{l}\text { Detection } \\
\text { Assay }\end{array}$ & $\begin{array}{l}\text { NOS } \\
\text { Score }\end{array}$ & $\begin{array}{l}\text { Case/ } \\
\text { Control }\end{array}$ & $\begin{array}{l}\text { Adjusted } \\
(95 \% \text { CI })\end{array}$ & Adjustments \\
\hline Alokail & 2013 & $\begin{array}{l}\text { Saudi } \\
\text { Arabia }\end{array}$ & $\mathrm{BC}$ & HB & $\begin{array}{l}\text { Retrospective } \\
\text { case-control }\end{array}$ & ELISA & 6 & $56 / 53$ & $1.90(0.62-5.70)$ & $\begin{array}{l}\text { age, menopausal status of } \\
\text { menarche }\end{array}$ \\
\hline Aly & 2013 & Egypt & $\mathrm{BC}$ & HB & $\begin{array}{l}\text { Retrospective } \\
\text { case-control }\end{array}$ & ELISA & 5 & $35 / 40$ & $1.26(1.21-1.93)$ & No \\
\hline Dalamaga & 2013 & Greece & $\mathrm{BC}$ & HB & $\begin{array}{l}\text { Retrospective } \\
\text { case-control }\end{array}$ & ELISA & 6 & $102 / 102$ & $1.17(1.03-1.34)$ & $\begin{array}{l}\text { age, date of diagnosis, education, } \\
\text { BMI, waist circumference, } \\
\text { family history of cancer, use of } \\
\text { exogenous hormones, smoking } \\
\text { history, adiponectin and leptin } \\
\text { concentration, inflammatory } \\
\text { markers, alcohol consumption, } \\
\text { smoking status }\end{array}$ \\
\hline Danese & 2012 & Italy & $\mathrm{CC}$ & HB & $\begin{array}{l}\text { Retrospective } \\
\text { case-control }\end{array}$ & ELISA & 6 & $40 / 40$ & $1.33(1.03-1.72)$ & $\begin{array}{l}\text { age, sex, BMI, lifestyle } \\
\text { parameters }\end{array}$ \\
\hline Gaudet $^{1}$ & 2010 & $\begin{array}{l}\text { United } \\
\text { States }\end{array}$ & $\mathrm{BC}$ & $\mathrm{PB}$ & $\begin{array}{l}\text { Prospective } \\
\text { nest case- } \\
\text { control }\end{array}$ & $\begin{array}{l}\text { Human } \\
\text { Adipokine } \\
\text { Panel }\end{array}$ & 7 & $234 / 231$ & $1.09(0.58-2.08)$ & $\begin{array}{l}\text { age, BMI, number of births, } \\
\text { age at first full-term birth, age } \\
\text { at menopause, and current } \\
\text { postmenopausal hormone use }\end{array}$ \\
\hline Gunter $^{1}$ & 2015 & $\begin{array}{l}\text { United } \\
\text { States }\end{array}$ & $\mathrm{BC}$ & $\mathrm{PB}$ & $\begin{array}{l}\text { Prospective } \\
\text { case-cohort }\end{array}$ & $\begin{array}{l}\text { Human } \\
\text { Adipokine } \\
\text { Panel }\end{array}$ & 6 & $875 / 820$ & $1.00(0.81-1.22)$ & $\begin{array}{l}\text { age, ethnicity, alcohol } \\
\text { consumption, family history } \\
\text { of breast cancer, parity, year of } \\
\text { menstrual cycling, age at first } \\
\text { child's birth, use of hormone } \\
\text { therapy, endogenous estradiol } \\
\text { levels, history of benign breast } \\
\text { disease, BMI and physical activity }\end{array}$ \\
\hline $\mathrm{Ho}^{1}$ & 2012 & $\begin{array}{l}\text { United } \\
\text { States }\end{array}$ & $\mathrm{CC}$ & $\mathrm{PB}$ & $\begin{array}{l}\text { Prospective } \\
\text { case-cohort }\end{array}$ & $\begin{array}{l}\text { Human } \\
\text { Adipokine } \\
\text { Panel }\end{array}$ & 6 & $427 / 797$ & $0.89(0.58-1.38)$ & $\begin{array}{l}\text { age, race, smoking status, ever } \\
\text { had colonoscopy, estrogen level, } \\
\text { insulin, waist circumference }\end{array}$ \\
\hline Hou & 2007 & China & $\mathrm{BC}$ & HB & $\begin{array}{l}\text { Retrospective } \\
\text { case-control }\end{array}$ & ELISA & 6 & $80 / 50$ & $1.34(1.11-2.35)$ & NA \\
\hline Kang & 2007 & Korea & $\mathrm{BC}$ & HB & $\begin{array}{l}\text { Retrospective } \\
\text { case-control }\end{array}$ & ELISA & 6 & $41 / 43$ & $2.77(1.40-5.50)$ & $\begin{array}{l}\text { age, BMI, status of menopause, } \\
\text { serum glucose and adiponectin }\end{array}$ \\
\hline $\operatorname{Liao}^{1}$ & 2012 & Finland & $\mathrm{RCC}$ & PB & $\begin{array}{l}\text { Prospective } \\
\text { nest case- } \\
\text { control }\end{array}$ & ELISA & 8 & $273 / 273$ & $1.15(0.80-1.51)$ & $\begin{array}{l}\text { number of years smoking, } \\
\text { presence of hypertension, history } \\
\text { of diabetes and physical activity }\end{array}$ \\
\hline Nakajima & 2010 & Japan & $\mathrm{CC}$ & HB & $\begin{array}{l}\text { Retrospective } \\
\text { case-control }\end{array}$ & ELISA & 7 & $115 / 115$ & $2.07(1.05-4.06)$ & NA \\
\hline Otake & 2010 & Japan & $\mathrm{CC}$ & HB & $\begin{array}{l}\text { Retrospective } \\
\text { case-control }\end{array}$ & ELISA & 5 & $98 / 26$ & $0.88(0.16-1.60)$ & No \\
\hline Sun $^{1}$ & 2010 & Taiwan & $\mathrm{BC}$ & HB & $\begin{array}{l}\text { Retrospective } \\
\text { case-control }\end{array}$ & ELISA & 7 & $380 / 760$ & $1.77(0.90-2.64)$ & $\begin{array}{l}\text { age, waist circumference, } \\
\text { hormone replacement therapy } \\
\text { use, family history of breast } \\
\text { cancer, age at enrollment, age at } \\
\text { menarche, age at first full-term } \\
\text { pregnancy, parity number }\end{array}$ \\
\hline
\end{tabular}

${ }^{1}$ Risk estimates were recalculated by the method proposed by Harmling et al.

Abbreviations: $\mathrm{HB}=$ Hospital Based; $\mathrm{PB}=$ Population Based; OR = Odds Ratio; $\mathrm{CI}=$ Confidence Interval; ELISA = Enzymelinked Immunosorbent Assay; BMI = Body Mass Index; NA = Unknown; NOS = Newcastle-Ottawa Scale; BC = Breast Cancer; $\mathrm{CC}=$ Colorectal Cancer; $\mathrm{RCC}=$ Renal Cell Cancer.

\section{Characteristics of included studies}

13 studies for meta-analysis performed on ORs were published from 2007 to 2016, involving 2756 cases and 3350 controls. 8 and 4 articles focused on breast and colorectal cancer, respectively [9-20]. 6 articles were conducted in Asia [9, 13-17], 3 in Europe [11, 12, 21], 3 in the USA [18-20], and 1 in Africa [10]. The ORs of most studies were adjusted for age and BMI. Circulating resistin levels were measured by enzyme-linked immunosorbent assay (ELISA) in 10 studies [9-17, 21], and by Human Adipokine Panel in 3 studies [18-20]. The quality score of studies ranged from 5 stars to 8 stars according to the 9-star Newcastal-Ottawa Scale [30]. General characteristics of 
Table 2: Characteristics of studies included in pooling SMD analysis

\begin{tabular}{|c|c|c|c|c|c|c|c|c|c|c|c|c|}
\hline \multirow{2}{*}{ Author } & \multirow{2}{*}{ Year } & \multirow{2}{*}{ Country } & \multirow{2}{*}{$\begin{array}{l}\text { Cancer } \\
\text { Type }\end{array}$} & \multirow{2}{*}{ Study Design } & \multirow{2}{*}{$\begin{array}{l}\text { Detection } \\
\text { Assay }\end{array}$} & \multirow{2}{*}{$\begin{array}{l}\text { NOS } \\
\text { Score }\end{array}$} & \multicolumn{3}{|l|}{ Cases } & \multicolumn{3}{|l|}{ Controls } \\
\hline & & & & & & & Number & Mean & SD & Number & Mean & SD \\
\hline Al-Haritby & 2010 & Saudi Arabia & $\mathrm{CC}$ & Retrospective case-control & ELISA & 4 & 60 & 19.44 & 8.46 & 60 & 5.45 & 2.73 \\
\hline Alokail & 2013 & Saudi Arabia & $\mathrm{BC}$ & Retrospective case-control & ELISA & 6 & 56 & 18.9 & 1.2 & 53 & 15.2 & 1 \\
\hline Aly & 2013 & Egypt & $\mathrm{BC}$ & Retrospective case-control & ELISA & 6 & 35 & 4.42 & 4.74 & 40 & 1.84 & 2.35 \\
\hline Assiri & 2015 & Saudi Arabia & $\mathrm{BC}$ & Retrospective case-control & ELISA & 6 & 82 & 26.24 & 1.59 & 68 & 22.69 & 2.58 \\
\hline 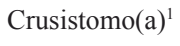 & 2016 & Portugal & $\mathrm{BC}$ & Retrospective case-control & ELISA & 7 & 30 & 11.6 & 7.31 & 29 & 7.51 & 3.6 \\
\hline Crusistomo(b) ${ }^{1}$ & 2016 & Portugal & $\mathrm{BC}$ & Retrospective case-control & ELISA & 7 & 47 & 16.1 & 10.37 & 48 & 10.4 & 9.75 \\
\hline Dalamaga & 2013 & Greece & $\mathrm{BC}$ & Retrospective case-control & ELISA & 6 & 102 & 11.2 & 6.4 & 102 & 7.7 & 4.85 \\
\hline Danese $^{1}$ & 2012 & Italy & $\mathrm{CC}$ & Retrospective case-control & ELISA & 6 & 40 & 8.96 & 3.42 & 40 & 4.97 & 1.07 \\
\hline Diakowska & 2014 & Poland & $\mathrm{EC}$ & Retrospective case-control & ELISA & 6 & 41 & 8.99 & 3.21 & 60 & 7.5 & 2.7 \\
\hline Gonullu $^{1}$ & 2009 & Turkey & $\mathrm{CC}$ & Retrospective case-control & ELISA & 5 & 36 & 6.1 & 3.3 & 37 & 4.5 & 1.5 \\
\hline Gunter $^{1}$ & 2015 & United States & $\mathrm{BC}$ & Prospective case-cohort & $\begin{array}{l}\text { Milliplex } \\
\text { Human } \\
\text { Adipokine } \\
\text { Panel }\end{array}$ & 5 & 875 & 12.1 & 4 & 821 & 12.3 & 4.3 \\
\hline $\mathrm{Ho}^{1}$ & 2012 & United States & $\mathrm{CC}$ & Prospective case-cohort & $\begin{array}{l}\text { Milliplex } \\
\text { Human } \\
\text { Adipokine } \\
\text { Panel } \\
\end{array}$ & 6 & 457 & 12.8 & 4.81 & 834 & 12.3 & 4.3 \\
\hline Hou & 2007 & China & $\mathrm{BC}$ & Retrospective case-control & ELISA & 6 & 80 & 26.35 & 5.36 & 50 & 23.32 & 4.75 \\
\hline Joshi & 2014 & Korea & $\mathrm{CC}$ & Retrospective case-control & ELISA & 6 & 100 & 4.9 & 2.3 & 100 & 2.8 & 1.7 \\
\hline Kang & 2007 & Korea & $\mathrm{BC}$ & Retrospective case-control & ELISA & 6 & 41 & 5.23 & 6.9 & 43 & 1.46 & 2 \\
\hline Kumor & 2008 & Poland & $\mathrm{CC}$ & Retrospective case-control & ELISA & 4 & 36 & 6.79 & 2.41 & 25 & 3.6 & 1.08 \\
\hline $\operatorname{Liao}^{1}$ & 2012 & Finland & $\mathrm{RCC}$ & $\begin{array}{l}\text { Prospective nest case- } \\
\text { control }\end{array}$ & ELISA & 8 & 273 & 9.27 & 2.73 & 273 & 9.28 & 2.83 \\
\hline Tulubas & 2014 & Turkey & $\mathrm{CC}$ & Retrospective case-control & ELISA & 6 & 30 & 18.77 & 5.09 & 30 & 13.36 & 6.36 \\
\hline
\end{tabular}

${ }^{1}$ Data was recalculated by the method proposed by Hozo et al.

Abbreviations: SD = Standard Deviation; CI = Confidence Interval; ELISA = Enzyme-linked Immunosorbent Assay; NOS = Newcastle-Ottawa Scale; $\mathrm{CI}=$ Confidence Interval; $\mathrm{BC}=$ Breast Cancer; $\mathrm{CC}=$ Colorectal Cancer; EC = Esophageal Cancer

the involved studies are shown in Table 1.

For pooling SMD analysis, 17 articles constituted 2421 cases and 2731 controls. Because 1 article consisted of 2 studies [24], a total of 18 studies were included. 8 studies were conducted in Asia [9, 13, 14, 22, 23, 26, 27, 29], 7 in Europe [11, 12, 21, 24, 25, 28], and 2 in the USA $[19,20] .9$ and 7 studies focused on breast and colorectal cancers, respectively [9-14, 19, 20, 22-24, 26-29] (Table 2).

\section{Pooling of studies and subgroup analysis}

The multivariate adjusted ORs for each study and the combined OR are present in Figure 2a. The combined OR for cancer risk was $1.20(95 \% \mathrm{CI}=1.10-1.30)$. There was no significant heterogeneity across the studies $\left(I^{2}=\right.$ $31.2 \%, P=0.133)$. So a fixed-effects model was adopted (Figure 2a). Further, subgroup analysis by sample size, 
Table 3: Subgroup analysis of pooling ORs of circulating resistin and cancer risk

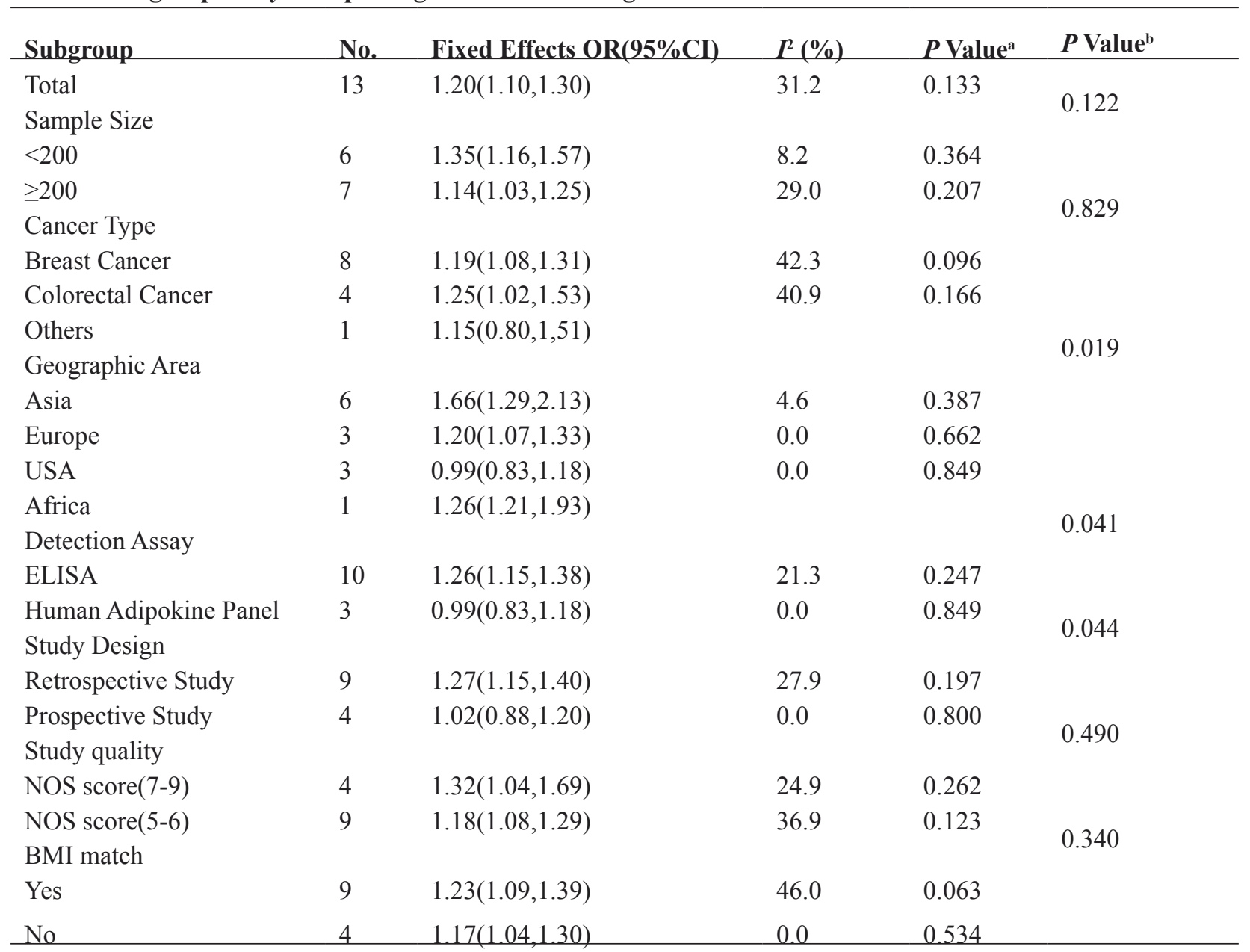

${ }^{a} P$-Value for heterogeneity within each subgroup.

${ }^{\mathrm{b}} P$-Value for heterogeneity between subgroups with meta-regression analysis

Abbreviations: No. = Number of studies; ELISA = Enzyme-linked Immunosorbent Assay; NOS = Newcastle-Ottawa Scale;

$\mathrm{OR}=$ Odds Ratio; $\mathrm{CI}=$ Confidence Interval; $\mathrm{BMI}=$ Body Mass Index

cancer type, geographic area, detection assay, study design, study quality, and BMI-match was conducted. High resistin levels were found to be associated with increased cancer risk in the studies of breast cancer $(\mathrm{OR}=$ $1.19,95 \% \mathrm{CI}=1.08-1.31)$, colorectal cancer $(\mathrm{OR}=1.25$, $95 \% \mathrm{CI}=1.02-1.53)$, Asia $(\mathrm{OR}=1.66,95 \% \mathrm{CI}=1.29$ $2.13)$, Europe $(\mathrm{OR}=1.20,95 \% \mathrm{CI}=1.07-1.33), \mathrm{ELISA}$ $(\mathrm{OR}=1.26,95 \% \mathrm{CI}=1.15-1.38)$, retrospective studies $(\mathrm{OR}=1.27,95 \% \mathrm{CI}=1.15-1.40)$. However, circulating resistin levels were similar between cases and controls in the studies of Human Adipokine Panel (OR $=0.99,95 \%$ $\mathrm{CI}=0.83-1.18)$, the USA $(\mathrm{OR}=0.99,95 \% \mathrm{CI}=0.83-$ $1.18)$, and prospective studies $(\mathrm{OR}=1.02,95 \% \mathrm{CI}=0.88$ 1.20) (Table 3).

18 studies were available to evaluate the SMD of circulating resistin levels with obesity-related cancer risk. Because of high heterogeneity $\left(I^{2}=95.7 \%, P=\right.$ $0.000)$, a random-effects model was used. Higher resistin levels were present in cancer patients $(\mathrm{SMD}=0.94$,
$95 \% \mathrm{CI}=0.63-1.25)$ (Figure $2 \mathrm{~b}$ ). Stratification analysis found that there was no significant association between circulating resistin levels and obesity-related cancer risk in prospective studies $(\mathrm{SMD}=0.02,95 \% \mathrm{CI}=-0.09$ 0.12) (Figure 2b). However, for retrospective studies, stratification analysis showed that resistin levels were always higher in cancer patients (Table 4).

\section{Heterogeneity analysis}

Sensitivity analysis was conducted to test the robustness of the results of meta-analysis by omitting one study every time. Results showed remaining studies yielded consistent results in pooling both ORs and SMD analysis (Figure S1). Galbraith plot analysis was used to spot the outliners as the potential sources of heterogeneity. For the pooling ORs analysis, one study was identified as the outlier and possible major source of heterogeneity [14] 
Table 4: Subgroup analysis of pooling SMD of circulating resistin levels and obesity-related cancer risk in retrospective studies

\begin{tabular}{|c|c|c|c|c|}
\hline \multirow{2}{*}{ Subgroup } & \multirow{2}{*}{$\begin{array}{l}\text { Number of } \\
\text { studies }\end{array}$} & \multirow{2}{*}{$\begin{array}{l}\text { Random-Effects } \\
\text { SMD }(95 \% \text { CI })\end{array}$} & \multicolumn{2}{|c|}{ Heterogeneity } \\
\hline & & & $I^{2}(\%)$ & $P$ \\
\hline Total & 15 & $1.15(0.80,149)$ & 90.0 & 0.000 \\
\hline \multicolumn{5}{|l|}{ Sample Size } \\
\hline$<100$ & 8 & $0.91(0.64,1.19)$ & 61.0 & 0.012 \\
\hline$\geq 100$ & 7 & $1.41(0.79,2.02)$ & 94.9 & 0.000 \\
\hline \multicolumn{5}{|l|}{ Cancer Type } \\
\hline Breast Cancer & 8 & $1.10(0.57,1.64)$ & 92.6 & 0.000 \\
\hline Colorectal Cancer & 6 & $1.33(0.87,1.79)$ & 80.1 & 0.000 \\
\hline Others & 1 & $0.51(0.11,0.91)$ & & \\
\hline \multicolumn{5}{|l|}{ Geographic Area } \\
\hline Asia & 8 & $1.39(0.82,1.95)$ & 93.0 & 0.000 \\
\hline Europe & 6 & $0.89(0.53,1.26)$ & \begin{tabular}{|l|}
76.6 \\
\end{tabular} & 0.001 \\
\hline Africa & 1 & $0.70(0.24,1.17)$ & & \\
\hline \multicolumn{5}{|l|}{ Study Quality } \\
\hline NOS Score(7-9) & 3 & $1.00(0.24,1.75)$ & 89.0 & 0.000 \\
\hline NOS Score(5-6) & 10 & $1.04(0.64,1.45)$ & \begin{tabular}{|l|}
89.7 \\
\end{tabular} & 0.000 \\
\hline NOS Score $(0-4)$ & 2 & $1.95(1.35,2.55)$ & 61.8 & 0.106 \\
\hline \multicolumn{5}{|c|}{ Resistin Levels in Controls } \\
\hline $0-5 \mathrm{ng} / \mathrm{ml}$ & 6 & $1.03(0.72,1.34)$ & 65.3 & 0.013 \\
\hline $5-10 \mathrm{ng} / \mathrm{ml}$ & 4 & $1.01(0.27,1.75)$ & 92.6 & 0.000 \\
\hline $10-15 \mathrm{ng} / \mathrm{ml}$ & 2 & $0.71(0.36,1.07)$ & 15.0 & 0.278 \\
\hline $15-\mathrm{ng} / \mathrm{ml}$ & 3 & $1.86(0.47,3.24)$ & 96.9 & 0.000 \\
\hline \multicolumn{5}{|l|}{ BMI Match } \\
\hline Yes & 10 & $1.40(0.90,1.91)$ & 91.0 & 0.000 \\
\hline No & 5 & $0.70(0.50,0.90)$ & 39.9 & 0.150 \\
\hline
\end{tabular}

Abbreviations: $\mathrm{NOS}=$ Newcastle-Ottawa Scale; $\mathrm{SMD}=$ Standardized Mean Difference $\mathrm{CI}=$ Confidence Interval; $\mathrm{BMI}=$ Body Mass Index

(Figure 3a). Except for the study, the association between resistin levels and cancer risk was still significant $(\mathrm{OR}=$ $1.18,95 \% \mathrm{CI}=1.09-1.28, I^{2}=5.0 \%, P$ (for heterogeneity analysis $)=0.396$ ) (Figure S2a). For the pooling SMD analysis of retrospective studies, three studies were identified as major contributors to high heterogeneity [9, 12, 22, 23] (Figure 3b). After excluding those studies, high resistin levels were still found in cancer patients (SMD = $0.75,95 \% \mathrm{CI}=0.63-0.87, I^{2}=39.3 \%, P$ (for heterogeneity analysis $)=0.087$ ) (Figure S2b). Furthermore, exploratory univariate meta-regression analysis was performed with sample size, cancer type, geographic area, detection assay, study design, study quality, and BMI-match as the covariates. For pooling ORs analysis, geographic area $(P=$ 0.019 , adjusted $\left.\mathrm{R}^{2}=50.02 \%\right)$, detection assay $(P=0.041$, adjusted $\left.\mathrm{R}^{2}=86.15 \%\right)$, and study design $(P=0.044$, adjusted $\mathrm{R}^{2}=13.31 \%$ ) were found to be significant factors (Table 3). For pooling SMD analysis of retrospective studies, meta-regression analysis revealed geographic area, BMI-match, size, and quality score could account for
$66.7 \%$ between-study variance (tau2 from 0.547 to 0.182 ).

\section{Estimation of publication bias}

Publication bias was examined by visual inspection of funnel plots and Egger's regression asymmetry test. For pooling ORs analysis, the shape of funnel plots did not indicate any evidence of publication bias (Figure 4a). Egger's regression test further confirmed this $(P=0.180)$ (Figure 4c). For pooling SMD analysis, the funnel plot had an asymmetrical distribution (Figure S3a). Egger's regression test also showed there was publication bias $(P=0.001)$ (Figure S3b). For pooling SMD analysis of retrospective studies, funnel plots had a slightly asymmetrical distribution (Figure 4b). However, Egger's regression test suggested publication bias was insignificant $(P=0.150)($ Figure $4 d)$. 


\section{DISCUSSION}

Currently, increased attention has been paid to the role of resistin in obesity-related cancers. Whether circulating resistin levels are higher in cancer patients is inconsistent. A meta-analysis was conducted by pooling both ORs and SMD. Higher resistin levels were found to be associated with increased obesity-related cancer risk. Serum resistin levels may be an independent risk of obesity-related cancers, but not a predictor. It may be the first attempt to synthesize the existing studies to evaluate the association of circulating resistin levels with obesityrelated cancer risk.

It is widely accepted that increased BMI and insulin resistance are associated with increased obesityrelated cancer risk. Resistin was considered as an adipocytokine secreted by adipocytes, monocytes and macrophages, especially in the visceral adipose tissue. Increasing evidence has shown human resistin could stimulate the production of pro-inflammatory cytokines and was an inflammatory biomarker [31, 32]. Chronic inflammation plays an important role in tumorigenesis. It seems plausible that resistin levels may be associated with the incidence of obesity-related cancer. However, the results of clinical trials are not always consistent. Metaanalysis allows a much greater possibility of reaching reasonably strong conclusions. The results of our metaanalysis suggested circulating resistin levels were higher in obesity-related cancer patients and an independent risk factor of obesity-related cancers. For pooling ORs analysis, stratification analysis showed significance only in those studies with colorectal cancer, breast cancer, ELISA detection assay, Asia and Europe, and retrospective studies. There was a lack of strong association in the
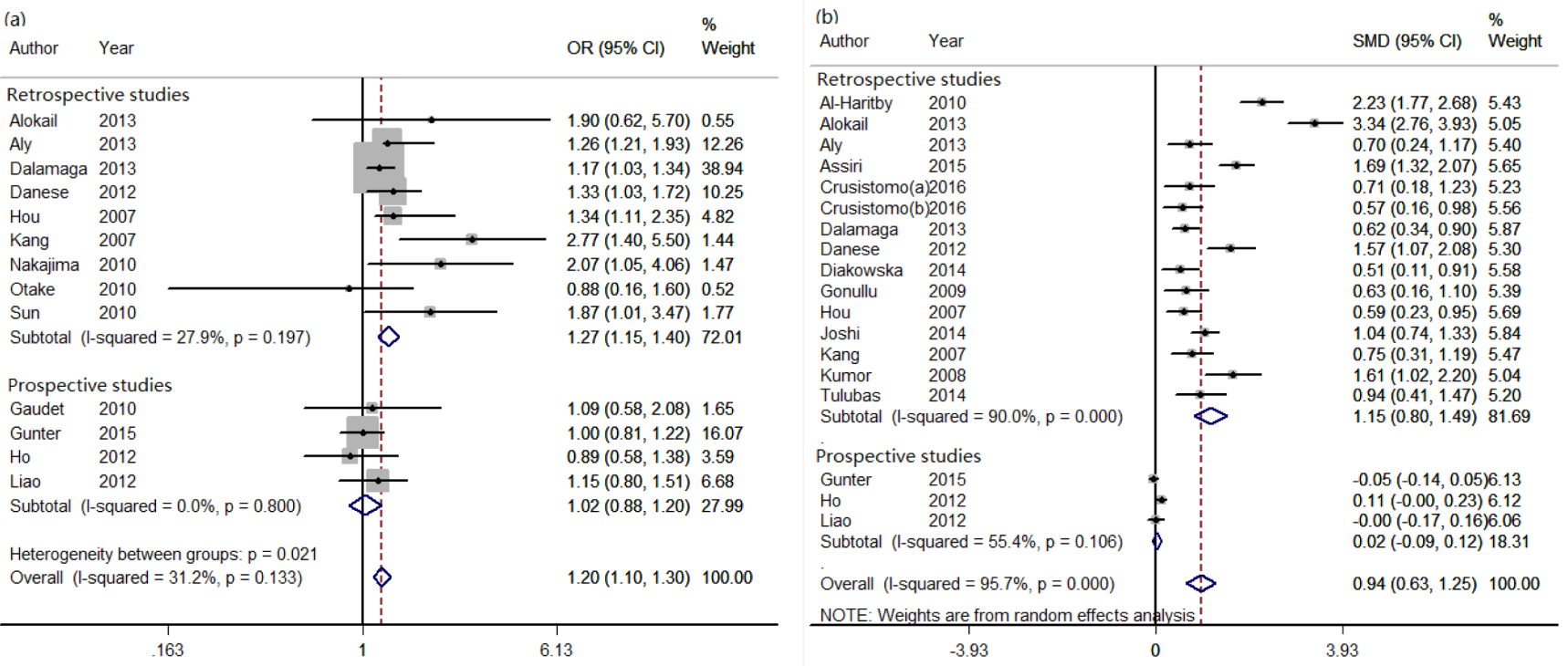

Figure 2: The effect of circulating resistin levels on obesity-related cancer risk in pooling ORs (a) and SMD (b) analysis.
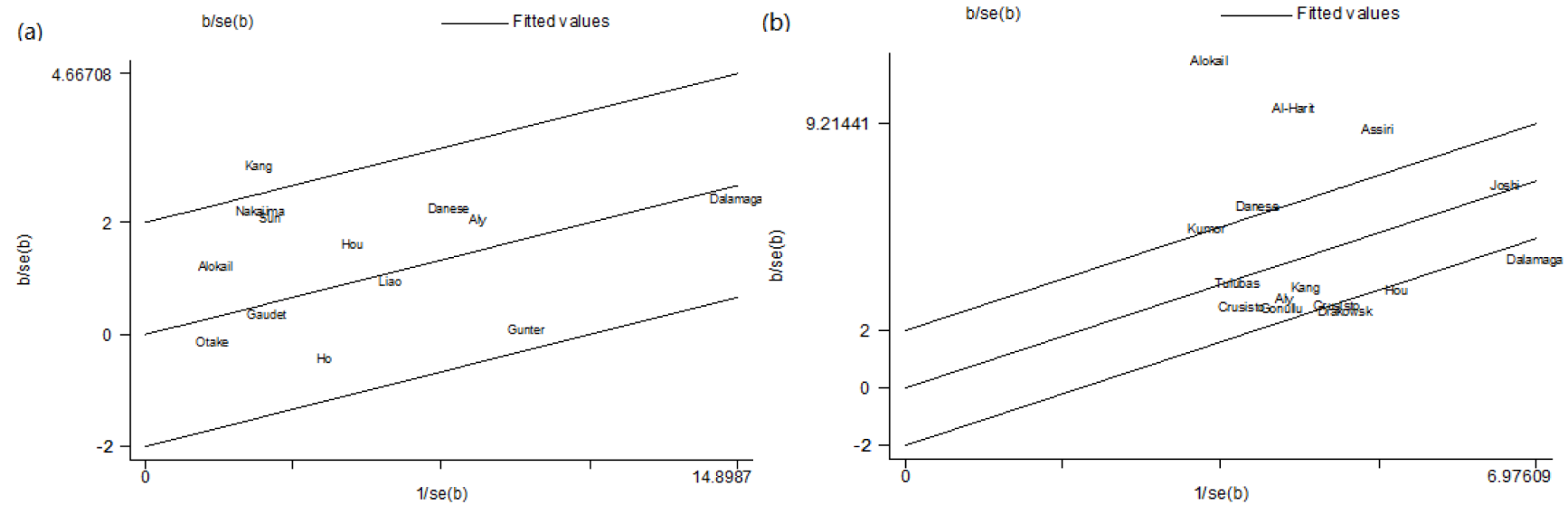

Figure 3: Galbraith plots of the association between circulating resistin levels and obesity-related cancer risk in pooling ORs analysis (a) and pooling SMD analysis of retrospective studies (b). 
studies of Human Adipokine Panel detection assay, the USA, and prospective studies. For the pooling SMD analysis, the association was also insignificant only in prospective studies. The prospective studies were mostly conducted in the USA, and detected by Human Adipokine Panel, while most of the retrospective studies were performed in Asia and Europe, and used ELISA to detect serum or plasma resistin levels. For prospective studies, the blood for resistin detection was drawn at the baseline of the follow-up. At that time, all subjects including those becoming cases later were still free of cancer. For retrospective studies, blood was collected when patients were diagnosed with cancer. This may contribute greatly to the differences of results between retrospective studies and prospective studies. It indicates circulating resistin levels may not be a predictor of obesity-related cancers at least in the USA. Prospective studies need to be conducted in Asia and Europe, and retrospective studies need to be conducted in the USA.

The heterogeneity of between-study is common in meta-analysis. Meta-analysis showed significant betweenstudy heterogeneity, especially in pooling SMD analysis. Sensitivity analysis, subgroup analysis, Galbraith plots, and meta-regression analysis were used to explore the potential causes of between-study heterogeneity and to reduce the heterogeneity. Sensitivity analysis didn't find any single study affected the estimated significance of pooled ORs or SMD. Galbraith plots indicated that 1 outlier study contributed to heterogeneity in pooling ORs analysis, while 4 outlier studies contributed to heterogeneity in pooling SMD analysis of retrospective studies. The results of the outlier studies greatly deviated from the pooling results. After omitting these studies, heterogeneity was insignificant. The pooling results didn't change significantly because of excluding the outlier studies. Meta-regression analysis found factors such as geographic area, detection assay, or study design almost completely accounted for some between-study variance in pooling ORs analysis, while geographic area, BMImatch, size, and quality score contributed significantly to heterogeneity of between-study in pooling SMD analysis of retrospective studies.

However, some limitations in the meta-analysis should be demonstrated, and the results should be prudently explained. First, our meta-analysis was limited to articles published in English. Slight publication bias may exist, especially for pooling SMD analysis. Some eligible articles may have been missed. Second, most
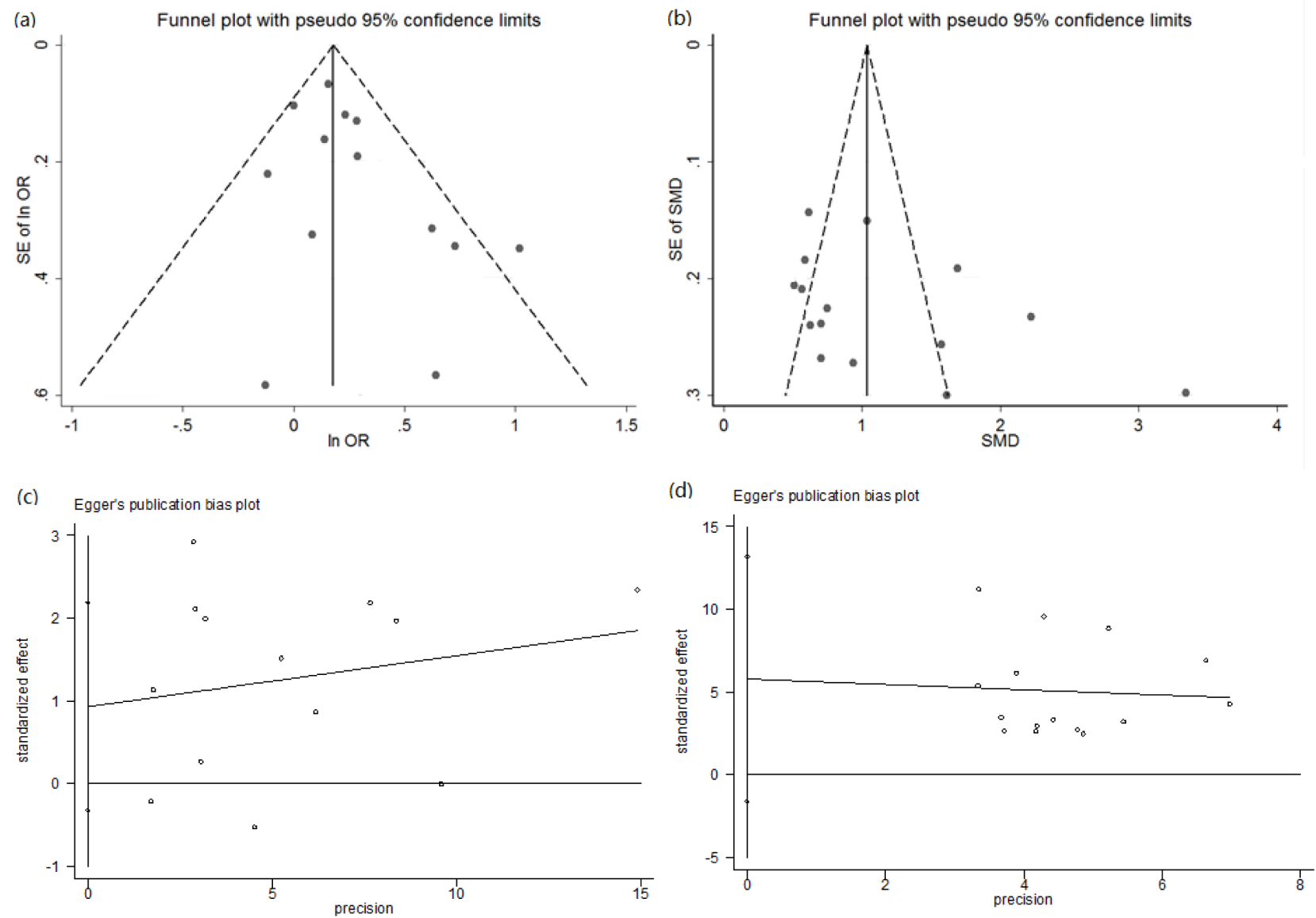

Figure 4: The funnel plots and Egger's bias plot of publication bias in pooling ORs analysis (a and c) and pooling SMD analysis of retrospective studies (b and d). 
studies included in our meta-analysis were case-control studies. It's widely known that case-control studies have inherent limits, such as selection bias, admission rate bias, detection signal bias. Third, the confounding factors in the studies for ORs analysis were inadequately considered due to various adjustments made in studies and some potential confounders were not considered in the majority of studies, such as diseases other than cancer, inflammatory conditions, drugs, and hormonal factors. Additionally, it should be noted that remarkable heterogeneity existed in pooling SMD analysis, and may have reduced the reliability of the meta-analysis.

In conclusion, this meta-analysis suggests circulating resistin levels may be higher in obesityrelated cancer patients than in normal controls, and an independent biomarker of obesity-related cancer risk. But it may not be a predictor of obesity-related cancer risk. Given the limited number of studies included as well as the significant heterogeneity, more randomized and largescale clinical trials, carefully controlled for potential confounding factors, are needed to confirm this association between resistin levels and obesity-related cancer risk in the future.

\section{MATERIALS AND METHODS}

\section{Search strategy}

A comprehensive literature screening was conducted for publications up to February 20th, 2016 from the following databases: (1) Pubmed (http://www.ncbi.nlm. nih.gov/pubmed/); (2) Embase (https://www.embase. com/); (3) Cochrane (http://www.cochranelibrary.com/). Search terms: "resistin, RETN", "cancer, tumor, neoplasm, carcinoma" and "serum, plasma, circulating, blood" were used in combination to retrieve the relevant literatures. Only papers written in English language were considered in this study. In addition, reference lists of articles were scrutinized to identify additional articles. This study was planned and conducted in accordance with standards of quality for reporting meta-analysis [33].

\section{Eligibility criteria}

Only studies meeting the following criteria were included: (1) the study must be an original epidemiological study; (2) the exposure of interest must be the serum or plasma resistin detected in blood samples; (3) the outcome of interest must be concerned with obesity-related cancers, including prostate, breast, colorectal, thyroid, renal, endometrial, pancreatic and esophageal cancers; (4) the study must report odds ratio (OR) or relative risk (RR), corresponding 95\% confidence intervals (CI), mean and standard deviation (SD), or data to calculate these.
Studies that did not refer to cancer, serum or plasma resistin, healthy controls, and that were conducted on animals, cells, or tissues were excluded. Two investigators (Wei Zheng and Wei-Jing Gong) reviewed all studies independently to identify and determine whether an individual study was eligible for inclusion in this metaanalysis. Any disagreement between the studies was resolved by consensus with a third reviewer (Zhao-Qian Liu).

\section{Data extraction}

Data was extracted and assessed by two independent researchers (Li-Ming Tan and Wei-Jing Gong) using the Newcastle-Ottawa Scale (NOS). Disagreements were resolved by consensus. Data extracted from eligible studies included first author's last name, year of publication, country of origin, study design, BMI, age, cancer type, sample size, resistin detection assay, confounders adjusted in multivariate analysis, RR or OR with corresponding $95 \% \mathrm{CI}$ for the risk of cancer incidence, mean and SD, or data to calculate them $[34,35]$.

\section{Statistical analysis}

Heterogeneity of effect size among studies was assessed by the Cochrane's $Q$-statistic test and $I^{2}$ test. If $P<0.05$ and $I^{2}>50 \%$, a random effect model was used, otherwise, a fixed effect model was used [36, 37]. Sensitivity analysis was performed to assess the influence of a single study on the summary results. When heterogeneity was present, subgroup analysis, Galbraith plot and meta-regression analysis were used to detect the potential sources of heterogeneity [38, 39]. Funnel plots and Egger's test were carried out to estimate publication bias $[40,41]$. Statistical analyses were performed using STATA version 12 (Stata Corp, College Station, TX, USA), and tests were two-sided with the criterion of statistical significance at $P<0.05$.

\section{ACKNOWLEDGMENTS}

This work was supported by the National High-tech R\&D Program of China (863 Program) (2012AA02A517), National Natural Science Foundation of China (81373490, 81573508, 81573463), Hunan Province National Science Foundation of China Grant (2015JJ1024), and Hunan Provincial Science and Technology Plan of China (2015TP1043).

\section{CONFILICTS OF INTEREST}

The authors declare no conflict of interest. 


\section{REFERENCES}

1. Arnold M, Pandeya N, Byrnes G, Renehan AG, Stevens GA, Ezzati M, Ferlay J, Miranda JJ, Romieu I and Dikshit R. Global burden of cancer attributable to high bodymass index in 2012: a population-based study. The Lancet Oncology. 2015; 16:36-46.

2. Paz-Filho G, Lim EL, Wong M-L and Licinio J. Associations between adipokines and obesity-related cancer. Front Biosci. 2011; 16:1634-1650.

3. Shikata K, Ninomiya T and Kiyohara Y. Diabetes mellitus and cancer risk: review of the epidemiological evidence. Cancer science. 2013; 104:9-14.

4. Steppan CM, Bailey ST, Bhat S, Brown EJ, Banerjee RR, Wright CM, Patel HR, Ahima RS and Lazar MA. The hormone resistin links obesity to diabetes. Nature. 2001; 409:307-312.

5. Chung WH, Kim TH, Chang IH and Myung SC. Relation of resistin to prostate cancer differentiation and aggressiveness. Korean Journal of Urology. 2009; 50:540546.

6. Dalamaga M. Resistin as a biomarker linking obesity and inflammation to cancer: potential clinical perspectives. Biomarkers in medicine. 2014; 8:107-118.

7. Kuo CH and Huang MS. Tumor associated dendritic cellderived resistin promoted lung cancer progression by increasing wolf-hirschhorn syndrome candidate 1/twist pathway. American Journal of Respiratory and Critical Care Medicine. 2013; 187.

8. Kim HJ, Lee YS, Won EH, Chang IH, Kim TH, Park ES, Kim MK, Kim W and Myung SC. Expression of resistin in the prostate and its stimulatory effect on prostate cancer cell proliferation. BJU international. 2011; 108:E77-E83.

9. Alokail MS, Al-Daghri N, Abdulkareem A, Draz HM, Yakout SM, Alnaami AM, Sabico S, Alenad AM and Chrousos GP. Metabolic syndrome biomarkers and early breast cancer in Saudi women: evidence for the presence of a systemic stress response and/or a pre-existing metabolic syndrome-related neoplasia risk? BMC cancer. 2013; 13:54.

10. Aly R, Zalam S and Sharaf F. Correlation between Adiponectin and Breast Cancer patients. Life Science Journal. 2013; 10.

11. Dalamaga M, Karmaniolas K, Papadavid E, Pelekanos $\mathrm{N}$, Sotiropoulos G and Lekka A. Hyperresistinemia is associated with postmenopausal breast cancer. Menopause (New York, NY). 2013; 20:845-851

12. Danese E, Montagnana M, Minicozzi AM, Bonafini S, Ruzzenente O, Gelati M, De Manzoni G, Lippi G and Guidi GC. The role of resistin in colorectal cancer. Clinica chimica acta. 2012; 413:760-764.

13. Hou WK, Xu YX, Yu T, Zhang L, Zhang WW, Fu CL, Sun Y, Wu Q and Chen L. Adipocytokines and breast cancer risk. Chinese medical journal. 2007; 120:1592-1596.

14. Kang JH, Yu BY and Youn DS. Relationship of serum adiponectin and resistin levels with breast cancer risk. Journal of Korean medical science. 2007; 22:117-121.

15. Nakajima TE, Yamada Y, Hamano T, Furuta K, Matsuda T, Fujita S, Kato K, Hamaguchi $\mathrm{T}$ and Shimada Y. Adipocytokines as new promising markers of colorectal tumors: adiponectin for colorectal adenoma, and resistin and visfatin for colorectal cancer. Cancer science. 2010; 101:1286-1291.

16. Otake S, Takeda H, Fujishima S, Fukui T, Orii T, Sato T, Sasaki Y, Nishise S and Kawata S. Decreased levels of plasma adiponectin associated with increased risk of colorectal cancer. World journal of gastroenterology. 2010; 16:1252-1257.

17. Sun $\mathrm{CA}, \mathrm{Wu} \mathrm{MH}$, Chu $\mathrm{CH}$, Chou YC, Hsu GC, Yang T, Chou WY, Yu CP and Yu JC. Adipocytokine resistin and breast cancer risk. Breast cancer research and treatment. 2010; 123:869-876.

18. Gaudet MM, Falk RT, Gierach GL, Lacey JV, Jr., Graubard BI, Dorgan JF and Brinton LA. Do adipokines underlie the association between known risk factors and breast cancer among a cohort of United States women? Cancer epidemiology. 2010; 34:580-586.

19. Gunter MJ, Wang T, Cushman M, Xue X, WassertheilSmoller S, Strickler HD, Rohan TE, Manson JE, McTiernan A, Kaplan RC, Scherer PE, Chlebowski RT, Snetselaar L, Wang D and Ho GY. Circulating Adipokines and Inflammatory Markers and Postmenopausal Breast Cancer Risk. Journal of the National Cancer Institute. 2015; 107.

20. Ho GY, Wang T, Gunter MJ, Strickler HD, Cushman M, Kaplan RC, Wassertheil-Smoller S, Xue X, Rajpathak SN and Chlebowski RT. Adipokines linking obesity with colorectal cancer risk in postmenopausal women. Cancer research. 2012; 72:3029-3037.

21. Liao LM, Weinstein SJ, Pollak M, Li Z, Virtamo J, Albanes D, Chow W-H and Purdue MP. Pre-diagnostic Circulating Adipokine Concentrations and Risk of Renal Cell Carcinoma. Carcinogenesis. 2012:bgs322.

22. Al-Harithy RN and Al-Ghafari AB. Resistin in human colon cancer. Increased expression independently of resistin promoter C-180G genotype. Saudi medical journal. 2010; 31:495-500.

23. Assiri A, Kamel HF and Hassanien MF. Resistin, visfatin, adiponectin, and leptin: risk of breast cancer in pre-and postmenopausal saudi females and their possible diagnostic and predictive implications as novel biomarkers. Disease markers. 2015; 2015.

24. Crisóstomo J, Matafome P, Santos-Silva D, Gomes AL, Gomes M, Patrício M, Letra L, Sarmento-Ribeiro AB, Santos L and Seiça R. Hyperresistinemia and metabolic dysregulation: a risky crosstalk in obese breast cancer. Endocrine. 2016; 53:433-42.

25. Diakowska D, Markocka-Maczka K, Szelachowski P and Grabowski K. Serum levels of resistin, adiponectin, and apelin in gastroesophageal cancer patients. Disease markers. 
2014; 2014:619649.

26. Gonullu G, Kahraman H, Bedir A, Bektas A and Yucel I. Association between adiponectin, resistin, insulin resistance, and colorectal tumors. International journal of colorectal disease. 2010; 25:205-212.

27. Joshi RK, Kim WJ and Lee SA. Association between obesity-related adipokines and colorectal cancer: a case-control study and meta-analysis. World journal of gastroenterology. 2014; 20:7941-7949.

28. Kumor A, Daniel P, Pietruczuk M and Malecka-Panas E. Serum leptin, adiponectin, and resistin concentration in colorectal adenoma and carcinoma (CC) patients. International journal of colorectal disease. 2009; 24:275281.

29. Tulubas F, Mete R, Oznur M and Topcu B. The role of adipocytokines in colon cancer and adenomas. Journal of Medical Biochemistry. 2014; 33:135-142.

30. Stang A. Critical evaluation of the Newcastle-Ottawa scale for the assessment of the quality of nonrandomized studies in meta-analyses. European journal of epidemiology. 2010; 25:603-605.

31. Silswal N, Singh AK, Aruna B, Mukhopadhyay S, Ghosh $\mathrm{S}$ and Ehtesham NZ. Human resistin stimulates the proinflammatory cytokines TNF- and IL-12 in macrophages by NF-B-dependent pathway. Biochemical and biophysical research communications. 2005; 334:1092-1101.

32. Reilly MP, Lehrke M, Wolfe ML, Rohatgi A, Lazar MA and Rader DJ. Resistin is an inflammatory marker of atherosclerosis in humans. Circulation. 2005; 111:932-939.

33. Stroup DF, Berlin JA, Morton SC, Olkin I, Williamson GD, Rennie D, Moher D, Becker BJ, Sipe TA and Thacker SB. Meta-analysis of observational studies in epidemiology: a proposal for reporting. Jama. 2000; 283:2008-2012.
34. Hamling J, Lee P, Weitkunat R and Ambühl M. Facilitating metaanalyses by deriving relative effect and precision estimates for alternative comparisons from a set of estimates presented by exposure level or disease category. Statistics in medicine. 2008; 27:954-970.

35. Hozo S, Djulbegovic B and Hozo I. Estimating the mean and variance from the median, range, and the size of a sample. BMC medical research methodology. 2005; 5:1.

36. DerSimonian R and Laird N. Meta-analysis in clinical trials. Controlled clinical trials. 1986; 7:177-188.

37. Mantel $\mathrm{N}$ and Haenszel W. Statistical aspects of the analysis of data from retrospective studies. Journal of the National Cancer Institute. 1959; 22:719-748.

38. Galbraith R. A note on graphical presentation of estimated odds ratios from several clinical trials. Statistics in medicine. 1988; 7:889-894.

39. Stanley TD and Jarrell SB. MetaRegression analysis: A quantitative method of literature surveys. Journal of Economic Surveys. 1989; 3:161-170.

40. Egger M, Smith GD, Schneider M and Minder C. Bias in meta-analysis detected by a simple, graphical test. Bmj. 1997; 315:629-634.

41. Stuck AE, Vandenbroucke J, Irwig L, Seagroatt V, Stratton I, Egger M, Langhorne P, Song F and Gilbody S. Bias in meta-analysis detected by a simple, graphical test. BMJ. 1998; 316:469-470. 